\title{
Nasal Inhalant Dosage Form
}

National Cancer Institute

\section{Source}

National Cancer Institute. Nasal Inhalant Dosage Form. NCI Thesaurus. Code C91153.

An inhalant intended for administration through the nose. 